of her stomach could be improved, and as a last resource it was determined to wash it out with a solution of sodium bicarbonate, 25 grains; sodium sulpho-carbolate, 15 grains ; euthymol, half a drachm; aq. ad one and half ounces. On March 22nd a No. 12 soft elastic catheter, indiarubber tube, and glass funnel were used; the catheter was passed through the month every morning about three hours after a meal. When the catheter entered the stomach some wind would generally escape and then from three to four ounces of thick slime and curdled milk would be evacuated through it. The stomach was then washed out and the resultant flaids were measured. Immediately after the stomach was cleansed a teaspoonful of the following mixture was given: spiritus ætheris chlorici, 15 minims; bismuth carbonate, 40 grains; sodium bicarbonate, 12 grains; :sodium sulpho-carbolate, half a drachm; decoctum hæmatoxyli, six drachms ; aq. cinnamom. ad one and a half ounces ; and a quarter of an hour later she was fed with from two to three ounces of human milk freshly drawn off. She was fed alternately from every two to three hours with from two to three ounces of human milk and one ounce of meat juice. She was not put to the breast as it was considered important that she should have no opportunity of overfilling the stomach. From this time her improvement was decided ; she spent very comfortable days but used to get rather restless by evening and was decidedly uncomfortable during the night. The day after the washing out was commenced she began to pass much more urine; three days later and subsequently she had almost normal motions. At the end of March the meat juice was stopped and she was put regularly to the breast. By April 2nd she had gained two ounces. By the 6th she had gained two more ounces. As her nights were so bad and the days were so good she was from this time washed out regularly night and morning at about three hours after ameal. Each time about three ounces of slime and curd were removed. On the 16 th she had improved so much that a trial was made to see if wash. ing out in the morning only would do, but her nights became restless again, and the evening washing-out of the stomach was resumed. By May 1st she had gained over one pound, her weight being $6 \mathrm{lb} 13 \mathrm{oz}$ She made uninterrapted progress, so that by the 12th the residue of slime and curd remored was reduced to between one and a half and two ounces. After the 19th she was only washed out occa. sionally. On the $23 \mathrm{rd}$, after 48 hours' interval, only one and a half ounces of residue were found. On the $30 \mathrm{ch}$ her weight was $8 \mathrm{lb} .4 \mathrm{oz}$. She had improved steadily ever since and on July 17 th she weighed over $12 \mathrm{lb}$. Her heart was now perfectly normal, the murmur having disappeared on March 29th.

There were two points that are worth noticing: 1. The patient's sensations of hunger were apparently cansed by the absence of digestible food in the stomach. She always showed signs of hunger two or three hours after feeding, even though her stomach, as ascertained by the catheter, might contain three or four ounces of slime and curd. After this had been removed, the stomach cleansed, and two or three ounces of milk given, she would appear to be satisfied for over two hours, although the stomach really contained less material than when she was very hungry. Her sensations of repletion depended on the nutritive value rather than on the quantity of the matter in the stomach. 2. Her attack of severe febrile muco-purulent gastrointestinal catarrh was rapidly followed by the appearance of a loud mitral systolic murmur which resembled in every way one due to rheumatic endocarditis. Soon after the stomach was brought into a healthier condition and the catarrh and fever had subsided, the murmur disappeared, and the heart has since then appeared to be healthy.

Cases of febrile disturbance, accompanied by some gastrointestinal trouble and followed by excited action of the heart and the development of an endocardial murmur, usually at the mitral orifice, are very common in children, and this case appears to show that the endocardill infection may have entered the body from the alimentary canal. It is always dangerous to generalise from only one case, but this one shows that an extremely severe attack of acute dilatation of the stomach was cured by syetematically cleansing that organ twice a day. As the treatment was persevered with the residue of slime and curd became less, and though at first from day to day no great difference could be seen, after every few days it was clear that the food given was being better digested, that less slime was secreted, and that the stomach was in a healthier condition and was regaining its normal functions.

The main point in the treatment appears to be the removal of the residues of slime and curd. This is analogous to the removal of residual urine and mucus in cases of aggravated catarrh of the bladder where the prostate is much enlarged. These residual fluids kept at the temperature of the body form most excellent incubating media for various species of bacteria and promptly infect and contaminate any fresh liquids, whether milk or urine, added to them. Drawing off the residual fluid and washing out the stomach in this case were quite as satisfactory in their results as emptying and washing out the bladder are in these cases of cystitis. Here I may mention that there was some difficulty in getting the catheter to pass the larynx and to enter the oesophagus, but with a little patience it could always be done. Towards the end of the treatment, when the stomach had been restored to a healthy condition, it was evident that it had regained its power of emptying itself through the pylorus. The child had regular natural stools and since then has shown no signs of having an abnormally large stomach or narrow pylorus. I have to thank Dr. Barlow for his valuable aid in February and March.

Brechin-place, S.W.

\section{A CASE OF COMPLETE TRANSVERSE SEPTUM OF THE VAGINA IMPEDING DELIVERY ; URETHRAL COITUS.}

\section{BY E. RUMLEY-DAWSON, L.R.C.P. LOND., M.R.C.S. ENG.}

THE patient was a primipara, aged 21 years, to whom I was called when in strong labour. Her history was as follows. She had had scarlet fever when she was six years of age, but her mother had never mentioned that the attack was in any way unusual, neither had she any recollection of pain or discomfort on sitting down or on micturition. She had never received any injury in the genital region. She had always been regular in her menstrual periods and they were not excessively or abnormally painful. She had never had any symptoms to lead her to think that there was anything abnormal in the vagina. She always had some leucorrhoa but had not seen a medical man for it. The nurse noticing that in spite of strong labour pains no progress seemed to be made at last sent for me.

On examining the patient in the left lateral position the index finger unknowingly and without pain passed direct into the bladder. On more deliberate and ocular examina. tion the external genitals were quite normal but the urethral orifice was found to be very dilated, while the vaginal orifice was small. The finger passed less than an inch into the vagina, meeting with an obstruction which, when a labour pain set in, felt like a large "bag of waters," and bulged with the pain. No cervix could be found and no fornices. The child's head could be felt per vaginam to be pushing down on to the obstruction and making it bulge. On examining per vaginam and rectum it was quite easy to get the obstruction between the fingers. It was found to be a rather thick transverse septum or diaphragm; this could also be plainly felt on examination per urethram and raginam. The septum between the finger-tips was felt to be about one quarter of an inch thick at the insertion into the vaginal wall, thinning down to the centre and becoming thick again at the opposite vaginal insertion. It was evident that a complete transverse vaginal septum was preventing the descent of the head. No hole or aperture could be found anywhere in the septum, but no examination under an anæsthetic was made. The bulging down of the septum by the advancing head so stretched it that even a small hole would have been revealed. The septum was not in the site of the hymen.

Though the patient denied being aware of any abnormality, sexual intercourse it was admitted had been diffcult from the first; while several months after marriage it became impossible, still later there had been less difficulty as the urethra was gradually dilated. The dilatation of the urethra had followed as the result of repeated attempts at coitus; she had not, however, been troubled with incontinence of urine, though urination had become more frequent. This increased frequency may bave been partly 
or even entirely, due to the pressure of the enlarged pregnant uterus. The septum was incised with a knife between two "pains," the incision was then enlarged with a finger tearing it through, the "waters" were rnptured, and the child very shortly after was delivered quite easily and naturally.

Remarks.-Cases of transverse septum of the vagina are distinctly rare, and when leading to urethral coitus, and later impeding labour, they become still more rare. Vaginal septa are either transverse or vertical, but only the former will be'considered now. Transverse vaginal septa are either congenital or acquired-i.e., inflammatory in origin. The one now described was evidently congenital, for though she had had scarlet fever there was no history of genital inflammation.

Dr. C. J. Cullingworth ${ }^{1}$ has recorded two cases of transverse vaginal septa. The first case, that of a widow, aged 38 years, was due to an attack of "irflammation at the age of 12 of the genital organs." There was an opening in the "thin and flexible septum" large enough to admit a uterire sound. Though she had been married nearly six years she was never pregnant and was " not aware of any difficulty or inconvenience in her marital relations." In the second case the septum obstructed labour; it was evidently a congenital case. There was always slight leucorrboea, and pain at the periods was "excessive" during the previous three years on the first day only of the flow. Under ether an opening of the size of the urethra was found in the septum, this was dilated and torn through, delivery soon following.

Dr. Cullingworth remarks that probably in all cases of transverse vaginal septa there is an opening, though often very small, and these small openings show how very enterprising the spermatozoa are. Further, he says that, "as in many other forms of vaginal abnormality, the urethra is of $t$ n four d much larger than usual"; possibly in his case also coitus had taken place per uretbram. In atresia hymenalis it was pointed out by Oldbam that the urethral orifice is more patulous than it is normally. Dr. C. R. Prance ${ }^{2}$ records two cases of transverse vaginal septa. Neither of the patients were pregnant; the first was unmarried and the second was married but was sterile; she soon became pregnant after the opening in the septum- of the size of a pin-hole only-was enlarged and the septum was destroyed. Dr. Gervis ${ }^{3}$ also narrates a case. The patient was a woman, aged 22 years. There was an annular hymen which was fairly defined, so that the septum was not a misplaced hymen. She had corstant leucorrboa in the intervals of her menstrual periods. A small probe only conld be passed through the hole in the septum, which was very thin. "Whetber it was congenital or due to early adhesive inflammation it was difficult to decide." Dr. Cullingworth ${ }^{4}$ in his paper says that the septum usually consists of "a thin, not very vascular, and easily lacerable membrane." Dr. R. S. Fancourt Barnes gives a case of a primipara, aged 21 years, where a "thick septum at least two inches in thickness existed." There was a small hole which admitted a nterine sound when some pressure was exerted in its introduction. The septum impeded labour.

Theše cases of vaginal septa are quite distinct from cases of cicatricial contraction or occlusion of the vagina. These latter have led to Cæsarean section to remove the child when the vagina has been so obliterated as to prevent birth per vaginam. Such a case was narrated by Stande in a paper on Cicatricial Contractions of the Vagina Impeding Labour. It led to an interesting discussion of the subject and its etiology. ${ }^{6}$ Dr. Galabin bas recorded a similar case. ${ }^{7}$

Concerning the dilated condition of the urethra, the result of admitted urethral coitus, most of the recorded cases of the latter have been in instances of absent vagina. In THE LANCET ${ }^{8}$ of 1869 it is mentioned that Dr. T. A. Emmet in his book on "Vesico-Vaginal Fistula" (1868) records two cases of coitus per urethram. In both cases the uterus and vagina were absent. The urine was easily retained in spite of the dilated urethra, "which was so patulous that the index finger could be introduced without difficulty" in one of the cases, while "in connexion the bladder bad been

1 THE LANCET, April 13th, 1889, p. 726

2 Tre

8 Transactions of the Obstetrical Society of London, vol. xxiv., p. 210. 4 Loc. cit.

5 Transactions of the Obstetrical Society of London, vol, xxr., p. 99. ${ }^{6}$ Brit. Med. Jour., Ep'tome, July 1st, 1893.

7 Transactions of the Obstetrical Society of London, vol. xviii., p. 252. 8 TAE LANCET, Feb. 20th, 1869, p. 260 entered without either party being aware of the malformation." Dr. J. O. Gooding ${ }^{9}$ records a case in which the lower portion of the vagina was undeveloped. The retained menses had burst throngh the urethra. The bladder could be entered with the greatest ease, even with two fingers, and this digital examination of the bladder was painless. There was no incontinence of urine. The patient was married and coitus was followed by immediate desire to micturate. Professor Langenbeck 10 recorded the following case. The patient was 23 years of age; menstruation began at the age of 14 years and the discharge took place per urethram. She bad been married for three years. "Coitus was effected by the urethra." The vagina was entirely absent and the uterus was rudimentary.

In the case the subject of this paper the vagina was not absent, and it subsequently fulfilled its function as the parturient passage, but the transverse septum in it prevented its proper use in coition and led to the urethra becoming used and consequently dilated. There can be no doubt that previously to, and just after, marriage there was an opening in the septum by which the menses escaped and by which eventually the spermatozoa were able to reach the uterus. That the patient became pregnant must bave been due to intercourse having occurred per vaginam. Subsequently to impregnation on an occasion of forcible coitus, perbaps even the identical occasion of her impregnation, the opening in the transverse vaginal septum must bave been torn; its edges thus freshered wonld be approximated by the collapse of the vaginal walls; this tear then evidently eventually healed up, so that at the time of labour no opening on examination conld be detected. Thus the upper part of the vagina and the already im regnated uterus became completely shut off. Urethral coitus must have followed as a result of this practical occlusion of the vagina, which probably became more and more marked as towards the latter balf of the pregnancy the increasing size and wejght of the foetus and uterus helped to force and bulge down the vaginal septum and thus entirely obliterate the vagina for practical purposes. So patulous bad the urethra become that the index finger pass $\epsilon d$ quite easily and painlessly into the bladder.

Leyton, N.E.

\section{AN OBSCURE AND COMPLICATED CASE OF CARCINOMA OF THE STOMACH.}

\section{BY CHARLES FRANCIS STEELE, L.R.C.P. LOND., M.R.C.S. ENG.}

CAsEs of carcinoma of the stomach, which are more or less atypical, are not uncommon. but it is, I think, rare to find practically none of the cardinal symptoms present, as in the case which I am about to describe, especially when the disease is well advanced. The patient was seen during his last illness, to my knowledge, by seven medical men, yetand I think not unnaturally so-the real state of affairs was not diagnosed, or indeed suspected, until the day before his death. In addition to the obscurity of its diagnosis the case presented interesting complications.

A well-to-do man, aged 46 years, consulted my father, Dr. Oharles Steele, for the first. time on August 1st, 1500, complaining of debility and depression, also of pain in the lower right chest and behind the lower right ribs, which was aggravated by gentle pressure. The hepatic region was tender in front, but the liver itself was not enlarged. The tongue was coated with a yellowish fur. "Rbeumatic" pains in the shoulders, the upper arms, and the pectoral regions were complained of. His general condition was a good deal relieved by saline aperients and rest in bed, and on August 12 th be was able to sit up and take food, which he much relished. It was suggested that when he became stronger a "course" at Droitwich might prove beneficial. In consequence of this remark the patient, a self-willed man, insisted upon going forthwith to Droitwich, and he went there on August 16th. The reports from his medical adviser there were not encouraging; the weakness progressed steadily, and after a stay of 18 days he was prevailed upon to return to his home. At Droitwich, by reason of the 